\title{
Characteristics, quality of life and control of respiratory allergic diseases caused by house dust mites (HDMs) in Spain: a cross-sectional study
}

\author{
Beristain Ana ${ }^{1}$ and Fernando de la Torre ${ }^{2^{*}}$ on behalf of the EpidMite Study Group
}

\begin{abstract}
This multicentre, cross-sectional study conducted in Spain assessed the clinical characteristics and quality of life of patients who were aged 14-55 years and had allergic rhinitis and/or asthma, which was due to house dust mite sensitisation, for at least 2 years. Overall, 296 patients were included; 60\% had allergic rhinitis (mostly persistent moderateto-severe) and $40 \%$ had rhinitis and asthma (mostly intermittent or mild-to-persistent). Patients with rhinitis had moderately reduced quality of life, which was significantly worse in adults than adolescents. The impact of asthma on quality of life was less pronounced than that of rhinitis. Our findings show that allergic asthma and/or rhinitis due to house dust mites have a moderately negative impact on quality of life, particularly in adults, and that quality of life is significantly influenced by rhinitis.
\end{abstract}

Keywords: Allergic asthma, Asthma control, Allergic rhinitis, House dust mites, Pharmacologic costs, Quality of life

The prevalence of house dust mite (HDM) sensitisation is high $[1,2]$ and represents a significant risk factor in the development of respiratory allergic disease [3-5]. Therefore, we conducted a multicentre, epidemiological, ambispective, cross-sectional study to determine the clinical characteristics of patients with HDM-induced respiratory allergic disease in Spain, along with their quality of life (QoL). A secondary objective was to assess the extent of asthma control during the year prior to inclusion in the study. Patients (aged 14-55 years) from 33 clinical groups working in Spain were eligible to participate if they had respiratory allergic disease (rhinitis or rhinitis and asthma with/without conjunctivitis) for at least 2 years that was due to HDM, had a positive skin prick test (wheal diameter $\geq 3 \mathrm{~mm}$ ) and/or were immunoglobulin E positive (class 2 or above), as measured by ImmunoCAP (Thermofisher, Uppsala, Sweden), and who had not received immunotherapy in the 5 years prior to

\footnotetext{
*Correspondence: Fernando.delatorremartinez@alk.net

${ }^{2}$ ALK-Abelló, S.A., C/Miguel Fleta 19, 28039 Madrid, Spain

Full list of author information is available at the end of the article
}

their inclusion in the study. The patients were included between October 2015 and February 2017, and gave written consent to participate in the study.

Rhinitis was assessed according to the Allergic Rhinitis and its Impact on Asthma (ARIA) guidelines [6] and asthma was assessed according to the Spanish Guideline on the Management of Asthma (GEMA) [7] and the Asthma Control Questionnaire (ACQ, Spanish adult version for all patients). Quality of life in patients with asthma was assessed by the mini version of the Asthma Questionnaire on Quality of Life (miniAQLQ). For rhinoconjunctivitis, QoL was determined using the mini Rhinoconjunctivitis Quality of Life Questionnaire (miniRQLQ) and the ESPRINT-15 [8]. Patients were asked about medication used for the symptomatic treatment of respiratory allergic disease caused by HDM in the year prior to their inclusion in the study. All information was collected during a single visit.

Overall, 296 patients (mean age of $29.5 \pm 10.0$ years) were evaluated (Table 1$)$. Most patients $(n=179 ; 60.5 \%)$ had rhinitis without asthma and 117 patients (39.5\%) had rhinitis with asthma. Almost all patients (98.7\%) were 
sensitised to Dermatophagoides pteronyssinus and 78.3\% of patients were sensitised to $D$. farinae. With respect to storage mites, $48.5 \%$ of patients tested positive for sensitivity to Lepidoglyphus, 31.5\% for Tyrophagus, 20.3\% for Glycyphagus and $15.5 \%$ for Blomia.

In the year prior to inclusion, $58.8 \%$ of patients used allergen avoidance measures; $10.3 \%$ of patients visited the emergency room due to their allergy. More patients with asthma (20.7\%) than with rhinitis (3.4\%) had an emergency room visit because of their respiratory allergic disease in the year prior to inclusion. Only one patient required hospitalisation due to asthma during this period prior to inclusion.

The ESPRINT-15 questionnaire was used to evaluate the overall QoL in patients with rhinoconjunctivitis, as well as specific domains including Symptoms, Daily life activities, Sleep, Psychological effects and General state of health (Table 2). No statistically significant differences were seen among patients with rhinitis and asthma compared with those who had rhinitis alone (with/without conjunctivitis). There was a significant difference between adolescents and adults in the domains of sleep, psychological effects, general state of health and overall QoL, with a greater impact in the adult population (Table 2).

Table 1 Baseline characteristics

\begin{tabular}{|c|c|c|c|c|}
\hline & \multicolumn{2}{|c|}{$\begin{array}{l}\text { Patients } \\
\text { with rhinitis } \\
\text { (without asthma) }\end{array}$} & \multicolumn{2}{|c|}{$\begin{array}{l}\text { Patients } \\
\text { with rhinitis } \\
\text { (with asthma) }\end{array}$} \\
\hline & $\mathrm{n}$ & $\%$ & $\mathrm{n}$ & $\%$ \\
\hline \multicolumn{5}{|l|}{ Age group } \\
\hline Adolescents (14-17 years) & 20 & 11.2 & 16 & 13.7 \\
\hline Adults (18-55 years) & 158 & 88.3 & 101 & 86.3 \\
\hline \multicolumn{5}{|l|}{ Gender } \\
\hline Female & 94 & 52.8 & 77 & 65.8 \\
\hline Male & 84 & 47.2 & 40 & 34.2 \\
\hline \multicolumn{5}{|l|}{ Conjunctivitis } \\
\hline Yes & 114 & 64.4 & 74 & 63.3 \\
\hline \multicolumn{5}{|l|}{ Rhinitis } \\
\hline Intermittent & 40 & 22.6 & 27 & 24.3 \\
\hline Persistent & 137 & 77.4 & 84 & 75.7 \\
\hline Mild & 48 & 27.1 & 29 & 25.7 \\
\hline Moderate-to-Severe & 129 & 72.9 & 84 & 74.3 \\
\hline \multicolumn{5}{|l|}{ Asthma } \\
\hline Intermittent & & & 47 & 41.2 \\
\hline Mild persistent & & & 45 & 39.5 \\
\hline Moderate persistent & & & 20 & 17.5 \\
\hline Severe persistent & & & 2 & 1.8 \\
\hline
\end{tabular}

There was a significant difference in the miniRQLQ scores between adolescents and adults in the activities domain, in other symptoms and in the overall score (Table 2). There were no differences between patients who had asthma in addition to rhinitis compared with those who only had rhinitis (with/without conjunctivitis). Asthma was associated with a lower impact on QoL compared with rhinitis (medians of different domains: $4.7-5.8$ ), with no statistically significant differences recorded between adolescents and adults. Patients had varying degrees of asthma control at baseline, as determined using ACQ scores: $45.2 \%$ of patients scored $>1.5$ (inadequate control of the disease), 34.5\% had adequate control (score $<0.75$ ) and the remaining $20.2 \%$ had partially controlled asthma $(0.75-1.5)$.

Having persistent severe asthma with additional conjunctivitis were the factors significantly associated with a worse result in the ACQ (higher score), in both the linear and the logistic model. Factors which reduced QoL in patients with rhinitis as measured by ESPRINT-15 and miniRQLQ included persistent, moderate-to-severe rhinitis with additional conjunctivitis and being female. For patients with asthma, adequately controlled asthma and absence of concurrent conjunctivitis were associated with improved quality of life.

This cross-sectional study of patients allergic to HDM in Spain indicates that respiratory allergic disease due to HDM has a moderate impact on patient QoL and this impact is influenced more by the presence of rhinitis than asthma. In some studies, sleep and daily activities were the QoL domains most affected in patients allergic to HDM $[9,10]$, but the current study found no differences between the different domains of rhinitis questionnaires. Several non-specific triggers can influence the severity of symptoms of respiratory allergic diseases, including changes in temperature, air pollution and cigarette smoke [11]. Variation in these factors could have been responsible for the differences in results between the present and previous studies. In the present study, differences between adults and adolescents were found in different domains of ESPRINT-15 and miniRLQL, indicating that both questionnaires provide complementary information.

Notwithstanding the limitations inherent in a crosssectional study design, this study shows that Spanish patients with allergic asthma and/or rhinitis due to HDM have moderately reduced QoL, which is significantly influenced by rhinitis, despite continuous treatment. Age is a determining factor in QoL in this population, and its impact is more negative in adults than in adolescents. 
Table 2 Results of the Quality of Life Questionnaires

\begin{tabular}{|c|c|c|c|}
\hline & Overall & Adolescents & Adults \\
\hline \multicolumn{4}{|c|}{ ESPRINT-15 Quality of Life Questionnaire } \\
\hline \multicolumn{4}{|c|}{ Symptoms (items 1-5) } \\
\hline Mean (SD) & $3.03(1.41)$ & $2.62(1.45)$ & $3.09(1.40)$ \\
\hline \multirow[t]{2}{*}{ Median [Q1, Q3] } & $3.00[2.00,4.00]$ & $2.20[1.50,3.90]$ & $3.20[2.00,4.20]$ \\
\hline & & 0.0635 & \\
\hline \multicolumn{4}{|c|}{ Daily life activities (items 6-8) } \\
\hline Mean (SD) & $2.23(1.56)$ & $1.85(1.30)$ & $2.28(1.59)$ \\
\hline \multirow[t]{2}{*}{ Median [Q1, Q3] } & $2.33[1.00,3.33]$ & $2.00[0.67,3.00]$ & $2.33[1.00,3.33]$ \\
\hline & & 0.1978 & \\
\hline \multicolumn{4}{|l|}{ Sleep (items 9-11) } \\
\hline Mean (SD) & $2.29(1.83)$ & $1.71(1.72)$ & $2.38(1.84)$ \\
\hline \multirow[t]{2}{*}{ Median [Q1, Q3] } & $2.00[0.67,3.67]$ & $1.33[0.17,2.83]$ & $2.00[0.67,3.67]$ \\
\hline & & 0.0338 & \\
\hline \multicolumn{4}{|c|}{ Psychological effects (items 12-14) } \\
\hline Mean (SD) & $2.38(1.70)$ & $1.82(1.52)$ & $2.47(1.72)$ \\
\hline \multirow[t]{2}{*}{ Median [Q1, Q3] } & $2.33[1.00,3.67]$ & $1.67[0.50,2.83]$ & $2.33[1.00,3.67]$ \\
\hline & & 0.0381 & \\
\hline \multicolumn{4}{|c|}{ General State of Health (item 15) } \\
\hline Mean (SD) & $3.08(0.94)$ & $2.72(1.06)$ & $3.13(0.91)$ \\
\hline \multirow[t]{2}{*}{ Median [Q1, Q3] } & $3.00[2.00,4.00]$ & $3.00[2.00,3.50]$ & $3.00[3.00,4.00]$ \\
\hline & & 0.0323 & \\
\hline \multicolumn{4}{|l|}{ Overall (items 1-15) } \\
\hline Mean (SD) & $2.57(1.33)$ & $2.13(1.22)$ & $2.63(1.34)$ \\
\hline \multirow[t]{2}{*}{ Median [Q1, Q3] } & $2.53[1.47,3.47]$ & $2.10[1.23,2.77]$ & $2.60[1.53,3.53]$ \\
\hline & & 0.0365 & \\
\hline \multicolumn{4}{|c|}{ MiniRQLQ Questionnaire } \\
\hline \multicolumn{4}{|l|}{ Activities (items 1-3) } \\
\hline Mean (SD) & $2.66(1.43)$ & $1.94(1.28)$ & $2.76(1.42)$ \\
\hline \multirow[t]{2}{*}{ Median [Q1, Q3] } & $2.67[1.67,3.67]$ & $1.67[1.00,2.67]$ & $2.67[1.83,3.67]$ \\
\hline & & 0.0014 & \\
\hline \multicolumn{4}{|c|}{ Practical problems (items 4-5) } \\
\hline Mean (SD) & $3.77(1.61)$ & $3.42(1.71)$ & $3.82(1.60)$ \\
\hline \multirow[t]{2}{*}{ Median [Q1, Q3] } & $4.00[2.50,5.00]$ & $3.50[2.00,4.75]$ & $4.00[2.50,5.00]$ \\
\hline & & 0.1730 & \\
\hline \multicolumn{4}{|c|}{ Nasal symptoms (items 6-8) } \\
\hline Mean (SD) & $3.54(1.48)$ & $3.24(1.55)$ & $3.58(1.47)$ \\
\hline \multirow[t]{2}{*}{ Median [Q1, Q3] } & $3.67[2.67,4.67]$ & $3.33[2.00,4.00]$ & $3.67[2.67,4.67]$ \\
\hline & & 0.1988 & \\
\hline \multicolumn{4}{|c|}{ Ocular symptoms (items 9-11) } \\
\hline Mean (SD) & $2.15(1.74)$ & $1.81(1.71)$ & $2.20(1.74)$ \\
\hline \multirow[t]{2}{*}{ Median [Q1, Q3] } & $2.00[0.67,3.33]$ & $1.33[0.17,3.67]$ & $2.00[0.67,3.33]$ \\
\hline & & 0.2071 & \\
\hline Other symptoms (ite & & & \\
\hline Mean (SD) & $1.56(1.71)$ & $1.56(1.71)$ & $2.13(1.59)$ \\
\hline Median [Q1, Q3] & $2.00[0.67,3.33]$ & $1.00[0.17,2.33]$ & $2.00[0.67,3.33]$ \\
\hline & & 0.0242 & \\
\hline Overall (items 1-14) & & & \\
\hline Mean (SD) & $2.76(1.29)$ & $2.32(1.32)$ & $2.83(1.28)$ \\
\hline Median [Q1, Q3] & $2.71[1.79,3.64]$ & $2.00[1.25,3.57]$ & $2.71[1.86,3.64]$ \\
\hline & & 0.0386 & \\
\hline
\end{tabular}




\section{These findings highlight the importance of effective management of upper airway symptoms in patients with respiratory allergic disease.}

\begin{abstract}
Abbreviations
ACQ: Asthma Control Questionnaire; Cl: confidence interval; GEMA: Guía Española del Manejo del Asma [Spanish Guideline on the Management of Asthma]; HDMs: house dust mites; miniAQLQ: mini Asthma Questionnaire on Quality of Life; miniRQLQ: mini Rhinoconjunctivitis Quality of Life Questionnaire; OR: odds ratio; Q1: 1st quartile; Q3: 3rd quartile; QoL: quality of life; SD: standard deviation.
\end{abstract}

\section{Acknowledgements}

This study would not be possible without the contribution of all the investigators of the EpidMite study, listed as follows in alphabetical order: Aldunate María Teresa, H. Reina Sofía (Navarra, Spain); Álvarez José Antonio, C.P. Oviedo (Asturias, Spain); Añó Miguel, Alergocantabria (Santander, Spain); Campos Gonzalo, H. Internacional Xanit (Málaga, Spain); Cardona Victoria, HU Vall D'Hebrón \& ARADyAL research network (Barcelona, Spain); Cruz Sergia, CH Torrecárdenas (Almería, Spain); De Luque Virginia, HU Virgen Macarena (Seville, Spain); Fernández Agustín, H NISA Virgen del Consuelo (Valencia); Figueroa Javier, HU Insular Gran Canaria (Las Palmas, Spain); Gaig Pere, HU Joan XXIII (Tarragona, Spain); Gómez Belén, H. Reina Sofía (Navarra, Spain); González Genoveva, Amb. Deusto (Vizcaya, Spain); Gutiérrez Diego, H Puerta del Mar (Cádiz, Spain); Iglesias Javier, H Sur (Sta Cruz de Tenerife); Jover Vicente, Rodríguez-Pacheco Ramón, Domenech Joan, HGU Elda (Alicante, Spain); Kraemer Raquel, Clínica Juaneda (Palma de Mallorca); Linares Tania, Escudero Elena, Rodríguez-Zuazo Idoia, HP Pontevedra (Pontevedra, Spain); López Damián, Sánchez-Guerrero Inmaculada HCU Virgen de Arrixaca (Murcia, Spain); Llamas Estrella, HG Granollers (Barcelona, Spain); Malet Alfons, Clínica Teknon (Barcelona, Spain); Maraví Antonio, Clínica Milenium (Seville, Spain); Martín-Lázaro Joaquín, HU Lucus Augusti (Lugo, Spain); Molina Montserrat, HG Hospitalet (Barcelona, Spain); Montoro Javier, H. Arnau de Vilanova (Valencia, Spain); Moreno Carmen, CH Torrecárdenas (Almería, Spain); Moya Carmen, CH Torrecárdenas (Almería, Spain); Pamies Rafael, H. Dr Gálvez (Málaga, Spain); Pérez-Pastor Laura, H. Viamed (Seville, Spain); Quiñones Dolores, H. Monte Naranco (Asturias, Spain); Raducán Isabella, Clínica TECMA (Valencia, Spain); Rodríguez Fernando, HU Marqués de Valdecilla (Santander, Spain); Rueda María, H. Quirón (Barcelona, Spain); Sánchez Cesárea, H. Juan Ramón Jiménez - UGC Neumología Alergia (Huelva, Spain); Sánchez-Machín Inmaculada, H. Tórax (Tenerife, Spain); Vidal Carmen, López Freire Sara, CHU Santiago (A Coruña, Spain); Zapata Juan José, Clínica de Alergia Dr. Juan J Zapata (Almería, Spain).

This article does not contain any studies with human participants performed by any of the authors, so no approval from an institutional review board was required for the production of this manuscript.

\section{Authors' contributions}

FT has written the manuscript. AB has reviewed the manuscript. The authors would also like to thank Mimi Chan of Springer Healthcare Communications, who performed an English language edit of this manuscript. This medical writing assistance was funded by ALK-A, SA. All authors read and approved the final manuscript.

\section{Funding}

This study was supported by ALK-Abelló, S.A., Madrid, Spain.

\section{Availability of data and materials}

The datasets used and/or analysed during the current study are available from the corresponding author on reasonable request.

\section{Ethics approval and consent to participate}

All patients gave written consent to take part in the study and the study was approved by the health authorities. The Ethical Committee of the Hospital Central de Asturias was the committee of reference.

\section{Consent for publication}

Not applicable.

\section{Competing interests}

A Beristain: no competing interest. Fernando de la Torre is an employee of ALK-Abelló, S.A., Madrid, Spain.

\section{Author details}

${ }^{1}$ H. Monte Naranco, Oviedo, Asturias, Spain. ${ }^{2}$ ALK-Abelló, S.A., C/Miguel Fleta 19, 28039 Madrid, Spain.

Received: 15 March 2019 Accepted: 5 July 2019

Published online: 06 August 2019

\section{References}

1. Sociedad Española de Alergia e Inmunología Clínica, editor. Factores epidemiológicos, clínicos y socioeconómicos de las enfermedades alérgicas en España (Alergológica 2015). Madrid: SEAIC; 2017.

2. Valero A, Justicia JL, Antón $\mathrm{E}$, et al. Epidemiology of allergic rhinitis caused by grass pollen or house-dust mites in Spain. Am J Rhinol Allergy. 2011;25(4):e123-8.

3. Knudsen TB, Thomsen SF, Nolte H, et al. A population-based clinical study of allergic and non-allergic asthma. J Asthma. 2009;46(1):91-4.

4. Linneberg A, Nielsen NH, Frølund $L$, et al. The link between allergic rhinitis and allergic asthma: a prospective population-based study. The Copenhagen Allergy Study. Allergy. 2002;57(11):1048-52.

5. Shaaban R, Zureik M, Soussan D, et al. Rhinitis and onset of asthma: a longitudinal population-based study. Lancet. 2008;372(9643):1049-57.

6. Bousquet J, van Cauwenberge P, Khaltaev N. Allergic rhinitis and its impact on asthma. J Allergy Clin Immunol. 2001;108(5):S147-334.

7. Bronconeumol A. Guía Española del Manejo del Asma [Spanish Guideline on the Management of Asthma]. Arch Bronconeumol. 2009;45(Suppl 7):2-35.

8. Valero A, Baró E, Sastre J, et al. Reference values for facilitating the interpretation of the ESPRINT-15 questionnaire (Spanish version). J Investig Allergol Clin Immunol. 2009;19(5):396-403.

9. Demoly P, Broué-Chabbert A, Wessel F, et al. Severity and disease control before house dust mite immunotherapy initiation: ANTARES a French observational survey. Allergy Asthma Clin Immunol. 2016;12(1):13.

10. Leger D, Bonnefoy B, Pigearias B, et al. Poor sleep is highly associated with house dust mite allergic rhinitis in adults and children. Allergy Asthma Clin Immunol. 2017;13:36.

11. Greiner AN, Hellings PW, Rotiroti G, et al. Allergic rhinitis. Lancet. 2011;378(9809):2112-22.

\section{Publisher's Note}

Springer Nature remains neutral with regard to jurisdictional claims in published maps and institutional affiliations. 